\title{
Schiffsarzt auf \\ Expeditionskreuzfahrten
}

\section{Tanja Kühnle}

Dipl.-Biol., Managing Editor

Die letzte Prüfung ist geschafft, das Medizinstudium beendet. Und wie geht es jetzt weiter? In unserer neuen Serie «Du findest deinen Weg!» stellen wir Ihnen in unregelmässigen Abständen aussergewöhnliche Berufsperspektiven für Mediziner vor. In dieser Ausgabe berichtet Dr. Ulrich Castelberg von seiner Tätigkeit als Arzt auf einem Expeditionskreuzfahrtschiff.

Herr Castelberg, wie kam es dazu, dass Sie Schiffsarzt geworden sind?

Ich habe nach meiner Pensionierung eine Antarktisreise gemacht, und der damalige Schiffsarzt erzählte mir, dass die Reederei noch Ärzte suche, und fragte mich dann, ob ich mitmachen möchte.

\section{Also haben Sie einfach Ja gesagt und angefangen?}

(lacht) Ganz so einfach war es nicht: Ich musste zunächst nach Hamburg, um mich vorzustellen. Und dann noch eine Woche an die Schifffahrtsschule nach Rostock. Das ist obligatorisch für alle, die auf dem Schiff arbeiten. Dort bekommt man eine Grundausbildung in Feuerbekämpfung, macht Rettungsübungen und lernt, wie man in kritischen Situationen mit den Passagieren umgehen muss. Das alles wird bei jedem neuen Dienstantritt an Bord auch nochmals schriftlich abgeprüft.

\section{Wie lange waren Sie jeweils auf See?}

Ich war nur zwei Mal pro Jahr für jeweils sechs Wochen auf dem Schiff. Jetzt darf ich nicht mehr als Schiffsarzt tätig sein, da ich mit 73 Jahren zu alt bin. So ist das Schifffahrtsgesetz.

\section{Und welche Routen haben Sie begleitet?}

Für mich war die «Faszination Eis» ausschlaggebend. Deshalb bin ich meist in die Arktis, nach Grönland Spitzbergen oder in die Antarktis gefahren.

\section{Waren Sie der einzige Arzt an Bord?}

Der Einzige, der im Dienst war, ja. Ich hatte allerdings eine Krankenschwester an meiner Seite. Ausserdem habe ich immer zu Beginn einer Reise die Passagierlisten nach Ärzten durchgeschaut und die Kollegen dann

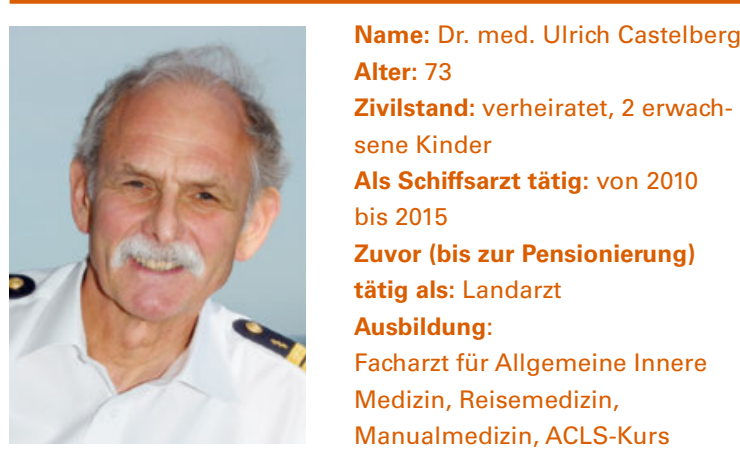

$\mathrm{zu}$ einem kleinen Aperitif eingeladen. So habe ich mir einen Überblick verschafft, wer im Notfall helfen könnte.

\section{Waren oft Ärzte unter den Passagieren?}

Ja, immer. Und ein Chirurg kann einen in den gängigsten Fällen besser unterstützen als ein Augenarzt oder Psychiater.

\section{Haben Sie die Unterstützung jemals gebraucht?}

Nein, das war nie nötig. Ich habe mich einmal mit einem früheren Kollegen via E-Mail beraten. Zudem besteht rund um die Uhr und die Welt für alle Schiffe auf See die Möglichkeit einer funkärztlichen telemedizinischen Beratung (TMAS). Oder man kann - sofern man nicht zu weit von der nächsten Station entfernt ist - einen Helikopter anfordern und den Patienten evakuieren. Aber ich habe alle Situationen letztendlich immer allein lösen können.

\section{Was für eine Ausbildung sollte man als Schiffsarzt haben?}

In der Regel werden Grundversorger gesucht, weil die 


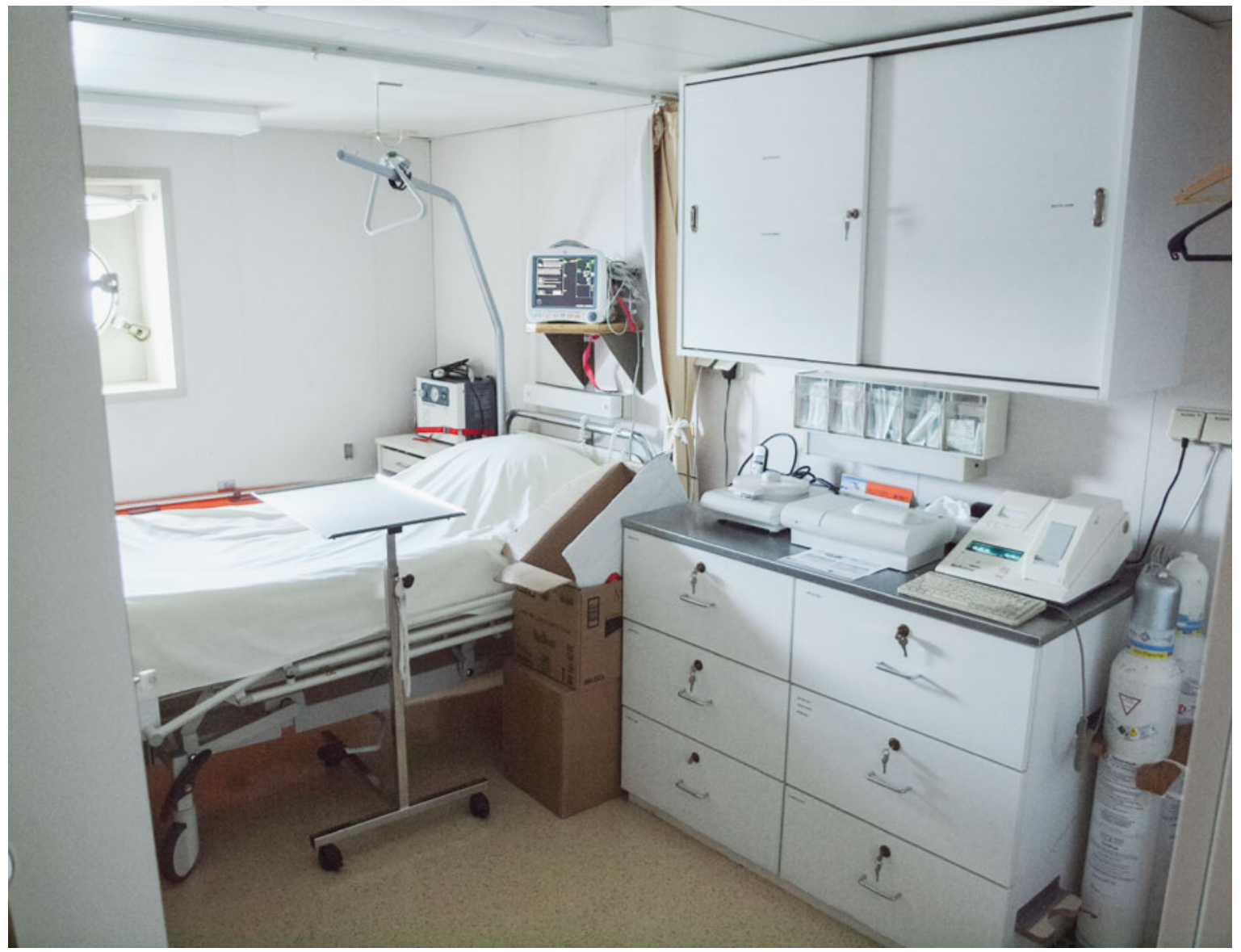

Die Krankenstation an Bord der MS Bremen: Der hintere Teil ist mit einem Bett, diversen Geräten und einem kleinen Labor ausgestattet. Weiter vorn (hier nicht zu sehen) findet die Sprechstunde statt.

Passagiere auf Expeditionsreisen meist etwas älter sind und entsprechende Krankheis- und Unfallrisiken haben. Ich sage immer: Schiffsarzt ist etwas für ausgediente Landärzte wie mich, denn wir wenden an, was wir all die Jahre über gelernt und gemacht haben.

\section{Würden Sie diesen Beruf auch jungen Ärzten empfehlen?}

Das kommt auf die Ausbildung an: Wenn jemand bereits drei Jahre auf der Notfallstation in einem grösseren Spital gearbeitet hat, dann schon. Dann wäre es anfangs höchstens ungewohnt, dass man nicht röntgen kann, denn auf vielen Schiffen gibt es bislang nur Ultraschallgeräte. Problematisch ist eher der Verdienst, denn davon kann man keine Praxis unterhalten, die während der Reise leer steht. Deshalb ist Schiffsarzt wohl eher etwas für pensionierte Ärzte, die sich noch nicht zur Ruhe setzen wollen.

\section{Wie war die Krankenstation an Bord ausgestattet?}

Die Station bestand aus zwei miteinander verbundenen Kabinen. Der vordere Teil war für die Sprechstunde und für das Administrative. Hinten gab es ein kleines Labor und ein Einzelbett unter anderem mit einem Überwachungsmonitor, einem Respirator und Defibrillator.

\section{Haben Sie verglichen mit einer Praxis an Land etwas vermisst?}

Nur ein paar kleine Dinge, die ich selbst mitgebracht habe: zum Beispiel eine bone-injection-gun (B.I.G.), eine selbsteinschiessende Kanüle für die direkte Infusion in den Markraum, denn im schweren Schockzustand ist oft keine Vene zu finden. Ausserderdem hatte ich ein paar Larynxtubusse dabei, falls die Intubation misslingen sollte. Beides habe ich zum Glück nie gebraucht. Ausserdem hatte ich immer ein paar HNO-Instrumente mitgenommen, die zum Beispiel nützlich waren, wenn jemand mit unstillbarem Nasenbluten in der Tür stand.

\section{Welche Erkrankungen sind auf Expeditions- kreuzfahrten typisch?}

Das Gängigste ist natürlich die Seekrankheit - da unsere Schiffe mit ungefähr hundert Metern Länge recht klein waren, konnte es auch mal ordentlich schaukeln. Und ansonsten das ganze Spektrum der Allgemeinpraxis, 
vor allem Frakturen, Luxationen und Fleischwunden. Es sind ja rund nochmals so viele Crewmitglieder wie Passagiere auf dem Schiff und diese sind vor Unfällen nicht gefeit.

\section{Hatte mal jemand an Bord einen Herzinfarkt?}

Zum Glück nicht. Ich hatte während meiner Zeit insgesamt drei Patienten mit akut dekompensiertem Vorhofflimmern, und ein Patient hatte eine Hirnblutung. Es kommen übrigens auch Appendicitis und Divertikulitiden vor. Aber es ist immer alles gut ausgegangen.

\section{Sind Sie auch für Zahnprobleme zuständig?}

Ja, meistens kamen Passagiere mit herausgefallenen Plomben oder entzündeten Wurzelkanälen zu mir.

\section{Waren Sie denn darüber informiert, wenn Passagiere mit heiklen Vorerkrankungen an Bord waren?}

Eigentlich sollte das der Fall sein, denn für die Antarktisreisen mussten unsere Passagiere ein Gesundheitszeugnis vorlegen, das vorgänging vom Hausarzt ausgestellt wurde. Unterwegs haben dann aber meist insbesondere diejenigen Passagiere Probleme gemacht, die angeblich ganz gesund waren und bei denen nichts im Zeugnis stand. Dafür gab es zwei Gründe: Entweder es wurden entscheidende Krankheiten absichtlich verschwiegen, damit der Passagier die Reise antreten kann. Oder der Patient wusste nichts von seiner Erkrankung, weil er nie zum Arzt geht.

\section{Durften Sie denn jemandem mit einer heiklen Vorerkrankung die Teilnahme an der Reise veweigern? Der Schiffsarzt ist in dieser Hinsicht der Berater des Ka- pitäns. Letzterer hat die Entscheidungskompetenz, im Bedarfsfall den Einstieg zu verweigern oder je nach Si- tuation auch die Route dem medizinischen Bedarf ent- sprechend abzuändern.}

\section{Haben Sie so einen Fall erlebt?}

Nein. Ich habe lediglich einmal Rücksprache mit dem Kapitän genommen, als ein Passagier mit einer erheblichen gesundheitlichen Vorbelastung an Bord war. Dieser Passagier hat uns dann schriftlich versichert, dass er um das Risiko weiss und dass er es selbst trägt. Hätte er das nicht getan, hätten wir ihn bei der nächsten Gelegenheit von Bord schicken müssen.

\section{Sind Sie selbst auch einmal krank geworden?}

Das ist mir zum Glück nie passiert. Aber einmal hatte ein Kollege von mir auf einem anderen Schiff ein Norovirus an Bord und es erwischte auch ihn. Also kam er in die Isolation, und die Krankenschwester musste alles allein regeln. Diese sogennanten "Outbreaks» sind sehr gefürchtet!

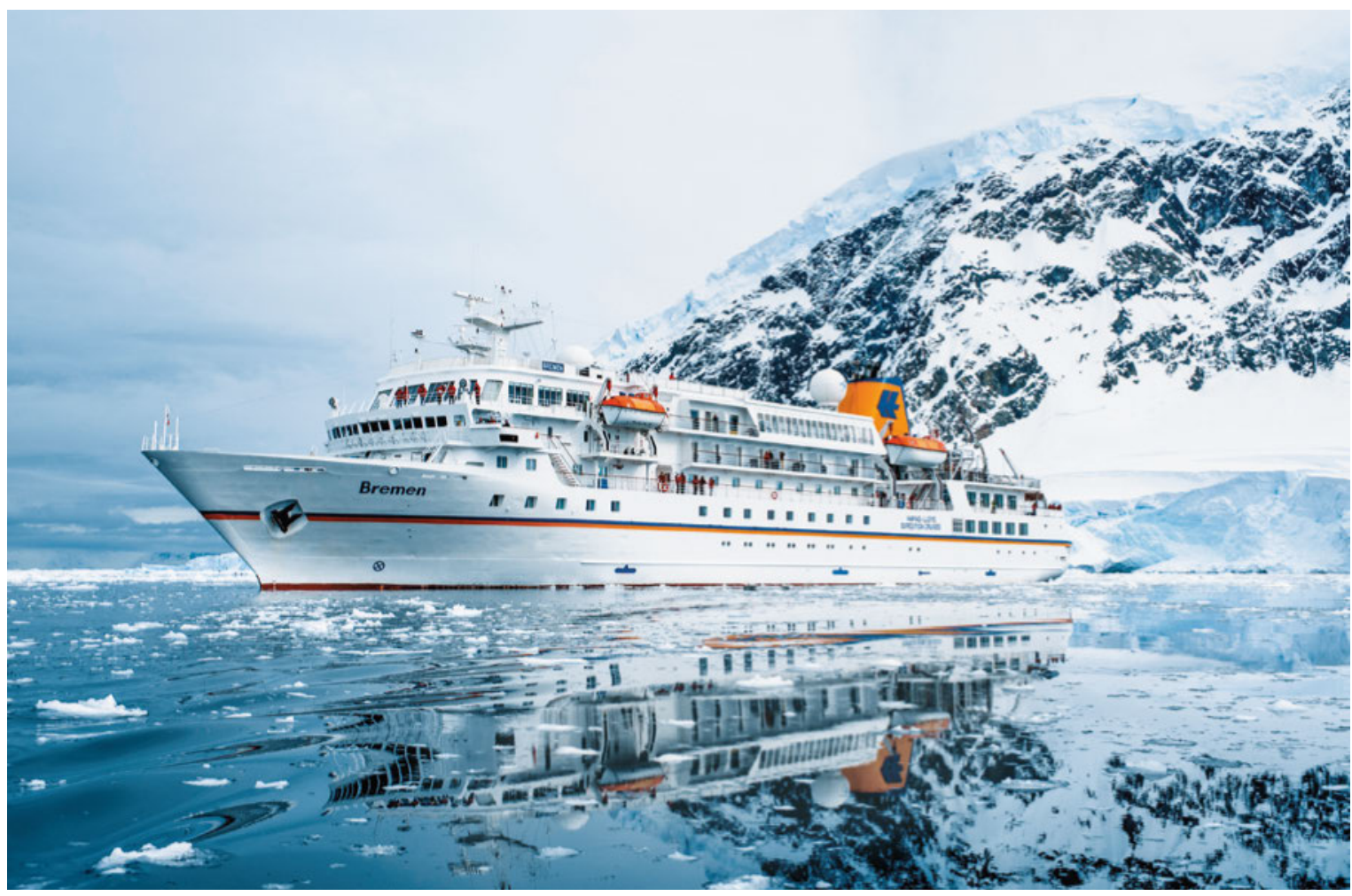

Die MS Bremen wurde 1990 in Japan gebaut und ist rund 110 Meter lang. An Bord sind bis zu 155 Passagiere und 100 Mannschaftsmitglieder. 


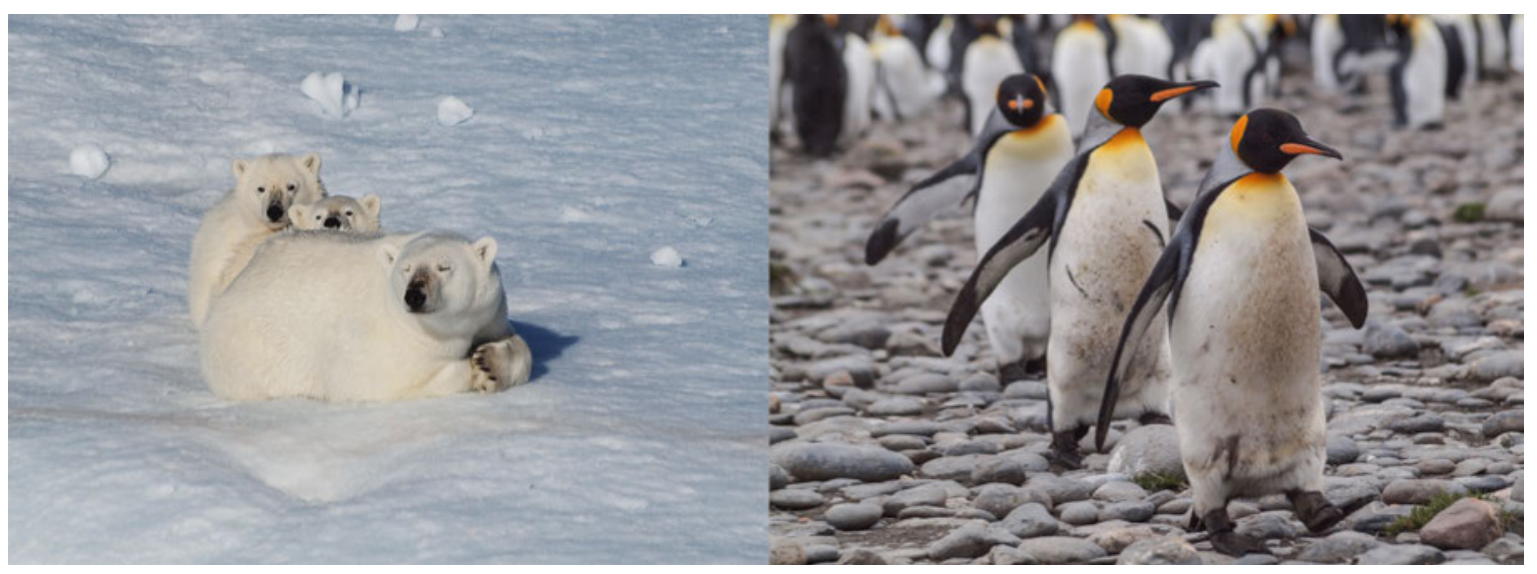

Eisbären und Kaiserpinguine in freier Natur erleben - ein Grund für Ulrich Castelberg, als Schiffsarzt an Bord der MS Bremen Reisen in die Arktis und Antarktis zu begleiten.

\section{Was hat es denn für Konsequenzen, wenn ein solches Virus an Bord ist?}

So ein Virus könnte das ganze Schiff lahmlegen. Denn jedes Mal, bevor das Schiff einen Hafen anläuft, muss der Arzt eine Gesundheitserklärung abgeben. Und wenn nur ein Passagier mit einer Durchfallerkrankung an Bord ist, kann es sein, dass sie den nächsten Hafen nicht mehr anlaufen dürfen.

\section{Gibt es auch Gesundheitsinspektionen an Bord?}

Ja, speziell wenn man in amerikanische oder kanadische Gewässer kommt. Im ersten Hafen, den man anläuft, kommt die Gesundheitsbehörde an Bord und nimmt das ganze Schiff auseinander. Das dauert etwa einen Tag lang und ist sehr mühselig. Küche, Restauration, Speise- und Wasservorräte und auch das Hospital mitsamt dem Doktor werden peinlich genau inspiziert.

\section{Durften Sie auch an den Ausflügen teilnehmen?}

Ja, das musste ich sogar. Denn bei Expeditionskreuzfahrten ins Eis geht man mit den Passagieren meist auf eine Insel und schaut die Tiere an. Und weil laut dem Antarktisvertrag nicht mehr als 100 Leute aufs Mal auf dem Land sein dürfen, haben wir uns immer in zwei Gruppen eingeteilt. Mit einer ging die Krankenschwester mit und mit der anderen ich.

\section{Wie waren Sie an Bord untergebracht?}

Als Schiffsarzt gehört man zu den Offizieren und hat auf dem Offiziersdeck eine Kabine für sich, die so gross ist, dass man jemanden mitnehmen kann. Die zweite Person zahlt dann nur die Anreise, der Rest ist gratis.

\section{Und wie waren Ihre Arbeitszeiten?}

Die Passagiere durften immer zu mir kommen, ich habe nie jemanden weggeschickt. Denn dafür war ich ja da! Ausserdem konnte ich so immer schon sehr früh eine Diagnose stellen und schnell helfen.

\section{Was hat Ihnen am Beruf des Schiffsarztes am meisten gefallen?}

Die Aufgabe an sich, also die ganze Zeit für die Passagiere verantwortlich zu sein. Manchmal ist man so weit von der Zivilisation entfernt, dass der Helikopter nur mit einer Verzögerung von 24 Stunden oder mehr eintreffen kann. Und manchmal ist man sogar so weit weg, dass man gar nicht mehr angeflogen werden kann. Ein bisschen Abenteuer ist also noch dabei, es ist nicht alles planbar.

Ausserdem war jede Reise ein unvergessliches Naturerlebnis. Seien es die jungen Eisbären, die mit ihrer Mama spielen, die Orkas, die das Schiff eine Weile begleiten, oder die grossen Pingiunkolonien in der Antarktis. Das Wetter konnte manchmal innerhalb von fünf Minuten vom Sonnenschein hin zum Schneefall wechseln. Ich hatte das Glück, dass ich das alles fünf Jahre lang erleben durfte. Das war eine wunderbare Zeit!

\section{Bildnachweis}

Poträtfoto Ulrich Castelberg und Foto MS Bremen: Hapag-Lloyd Cruises Foto von der Krankenstation, den Kaiserpinguinen und Eisbären: Ulrich Castelberg

Haben Sie als Mediziner auch einen aussergewöhnlichen Beruf, den Sie unseren Lesern gern vorstellen möchten? Dann freuen wir uns auf Ihre Bewerbung per E-Mail an: tkuehnle[at]emh.ch 